\title{
Intoxicação por Senecio spp. (Compositae) em bovinosno sul do Brasil
}

\author{
Poisoning in cattle by Senecio spp. (Compositae) in Southern Brazil
}

\author{
João Roberto Basile ${ }^{1}$ J oão Maria Ferraz Diniz² ${ }^{2}$ Werner Okano' ${ }^{1}$, Silvana Maris Cirio ${ }^{3} \&$ Luiz Carlos Leite ${ }^{3}$
}

\begin{abstract}
RESUMO
Plantas do gênero Senecio são nativas em várias regiões do mundo e consideradas causadoras de uma enfermidade de caráter enzoótico em bovinos, com importante reflexo na produção animal. Este trabalho descreve a ocorrência de intoxicação por Senecio spp. em bovinos de leite e de corte, nos estados de Santa Catarina e Paraná, respectivamente. Na granja leiteira, de 250 fêmeas holandesas morreram 31 (12,4\%), sendo 14 bezerras, 9 novilhas e 8 vacas. Os animais recebiam feno de alfafa à vontade, cujos fardos apresentaram infestação média de 3\% da planta. Na segunda granja haviam 20 bois mestiços soltos em campo nativo infestado por Senecio brasiliensis. Não havia deficiência de pastagem. Os animais foram abatidos após a morte do primeiro intoxicado. Os animais afetados mostraram inapetência, depressão, incoordenação motora, andar em círculo, agressividade, diarréia e/ou coprostase, tenesmo, emagrecimento progressivo e, em alguns casos, edema subcutâneo, prolapso de reto e paraplegia do trem posterior. Os achados de necropsia eram fígado com graus variáveis de endurecimento e vesícula biliar distendida com bile espessa; petéquias e sufusões nas serosas torácicas e abdominais; edema do tecido subcutâneo, mesentério, pregas do abomaso e parede da vesícula biliar. As alterações histopatológicas foram as do fígado, caracterizadas por fibrose periportal e muitas vezes estendendo-se entre os lóbulos hepáticos, discreta a moderada megalocitose, hiperplasia de ductos biliares, vacuolização e necrose de hepatócitos, esteatose, infiltrados histiolinfoplasmocitários e neutrofílicos periportais. Nefrose tubular com perda de proteínas, encefalomalácia focal, hemorragias focais no pulmão e coração, congestão esplênica e enterite catarral foram menos freqüentes. O diagnóstico baseou-se nos sinais clínicos, nos achados anátomopatológicos e na presença da planta misturada no feno de alfafa ou na pastagem.
\end{abstract}

Descritores: plantas hepatotóxicas, Senecio brasiliensis, Compositae, bovinos, alcalóides pirrolizidínicos.

\section{ABSTRACT}

Senecio spp. are worldwide naturally occurring plants usually associated with the appearance of an enzootic disease in cattle of significance to animal production. The authors describe the occurrence of Senecio spp. poisoning in dairy and beef cattle in Southern Brazil, in the states of Santa Catarina and Paraná, respectively. In the dairy herd an outbreak caused the death of $31(12.4 \%)$ out of 250 females, being 14 calves, 9 heifers and 8 cows. The animals received self feeding alfalfa hay ration which was later found to contain about $3 \%$ of the plant. In the second farm there was 20 crossbred males which had been grazing on native field infested by Senecio brasiliensis. There was no deficiency of pasture. The animals were slaughtered just after the death of one. The affected animals showed anorexy, depression, incoordenation of gait, circling, agressivity, diarrhea and/or constipation, tenesmus, progressive weight loss and, in some cases, subcutaneous edema, rectal prolapse and ataxia of the hind-legs. At necropsy, were observed the liver more firm than usual and fibrous when cut and the gallbladder distended with thick bile; petechial hemorrhages in all serosal surfaces, subcutaneous tissue edema, mesentery, abomasal folds and gallbladder. The histopathologic changes consisted of different degrees of fibrous proliferation in the porta spaces often extending into liver lobules, discrete to moderate megalocytosis, hyperplasia of the biliary ducts, fatty degeneration, vacuolation and necrosis of hepatic cells and periportal monomorphonuclear and neutrophillic cells infiltration. Tubular nephrosis with protein lossing, focal spongy degeneration, focal hemorrhages of lung and heart, spleenic congestion and catarrhal enteritis were present in some cattle. The diagnosis was based on the clinical signs, on the anatomo-pathological examinations as well as in the presence of the toxic plant mixed in the hay ration or in the pasture.

Key words: hepatotoxic plants, Senecio brasiliensis, Compositae, cattle, pyrrolizidine alkaloids. 


\section{INTRODUÇÃo}

Plantas do gênero Senecio são nativas em várias regiões do mundo e consideradas causadoras de uma enfermidade de caráter marcadamente enzoótico em bovinos, com importante reflexo na produção animal.

Através da literatura constata-se que várias espécies animais, inclusive humanos, são afetadas, porém a intoxicação natural é mais comum em bovinos e eqüinos [12].

No Brasil, das 128 espécies existentes [17], Senecio brasiliensis (maria-mole, berneira, flor de outubro, tasneirinha ou flor das almas) é a mais difundida em campos nativos e cultivados em toda região sul e em pequenas áreas na região sudeste.

O princípio tóxico das espécies de Senecio inclui um grupo de potentes hepatotoxinas, conhecidas como alcalóides pirrolizidínicos [3].

A intoxicação natural e experimental por várias espécies de Senecio em bovinos já foi descrita na Grã-Bretanha, Alemanha, Nova Zelândia, Canadá, Estados Unidos, África do Sul, Argentina, Uruguai e Paraguai [21]. No Brasil, publicações relatando a ocorrência de intoxicação natural são escassas. A distribuição dos surtos diagnosticados em vários pontos do Rio Grande do Sul [1], e o impacto da doença são praticamente desconhecidos dos veterinários.

As plantas do gênero Senecio constituem-se como uma das principais causas de mortes em bovinos adultos no Rio Grande do Sul [1,5,14,20]. A ingestão diária de 0,6 a 5,0g da planta verde por $\mathrm{Kg}$ de peso vivo, por um período de um a 8 meses, provoca lesões hepáticas progressivas e irreversíveis [22].

Esta comunicação visa fornecer subsídios para a clínica veterinária, alertando os colegas de campo e autoridades sanitárias do Paraná e Santa Catarina para a crescente importância da intoxicação por Senecio spp. em nosso meio.

\section{MATERIAIS E MÉTODOS}

Os dados utilizados no presente trabalho são oriundos de duas propriedades: A. uma granja leiteira situada na região nordeste de Santa Catarina e B. um sítio na região sul do Paraná.

Os dados epidemiológicos, os sinais clínicos e os achados de necropsia de 15 animais da propriedade A e de um animal da propriedade B foram observados nos próprios locais.
O material submetido ao exame histopatológico consistia de amostras de fígados de 16 animais e algumas amostras de rim, cérebro, pulmão, coração, intestino, linfonodos e baço. Fragmentos destes órgãos foram fixados em solução de formol a $10 \%$, processados rotineiramente em microtomia de parafina, corados pelas técnicas de Hematoxilina de Harris e Eosina e Tricrômico de Mallory e examinados por microscopia óptica. Lâminas foram selecionadas e fotomicrografadas. Do animal necropsiado no sítio B foi enviado material para exame de raiva.

\section{RESULTADOS}

\section{Histórico e sinais clínicos}

Na granja leiteira de Santa Catarina havia um rebanho médio de 250 fêmeas da raça Holandesa mantidas em semiconfinamento. Os animais jovens e adultos começaram a ser alimentados com feno de alfafa de determinada procedência. Os primeiros casos clínicos e mortes de bezerras (4 a 6 meses de idade) aconteceram 8 meses após. Entre 9 e 15 meses seguintes ocorreram casos esparsos em animais jovens e adultos. A partir de 16 meses após o início da ingestão, os casos clínicos e mortes tornaram-se mais freqüentes.

Somente com o resultado dos exames histopatológicos, suspeitou-se da intoxicação e a inspeção minuciosa de vários fardos de alfafa evidenciou a infestação média de 3,0\% por Senecio spp. Suspenso o fornecimento dessa alfafa, ainda ocorreram mortes durante 3 a 4 meses. Portanto, no período de 12 meses morreram 31 cabeças $(12,4 \%)$, sendo 14 bezerras de 4 a 10 meses, 9 novilhas de 12 a 24 meses e 8 vacas de 3 a 10 anos de idade. Dos animais que adoeceram apenas uma novilha que apresentou sintomas nervosos e prolapso retal, conseguiu recuperar-se. No final deste período foram abatidas outras 7 vacas, tão logo surgiram os primeiros sinais clínicos de intoxicação.

A evolução da doença variou da forma aguda, em bezerros que morreram 1 a 2 dias após o aparecimento dos primeiros sinais clínicos até a crônica, em vacas que resistiram por 2 a 3 semanas. Os animais mostraram inapetência, depressão, diarréia com fezes verde-escuras líquidas ou copros-tase acompanhada de tenesmo (contrações abdominais, gemidos de dor, e alguns poucos, apresentaram prolapso de reto). Sintomas nervosos foram freqüentes e caracterizaram-se pelo andar cambaleante ou em cír- 
culo, agressividade, apoio da cabeça em qualquer obstáculo e um caso de paraplegia do trem posterior (Figura 1). Todos os animais mostraram emagrecimento progressivo.

Na propriedade do sul do Paraná haviam 20 bois mestiços criados extensivamente em campo nativo para engorda. Recebiam suplementação mineral, vacinações contra febre aftosa, manqueira e desverminação periódica. Era grande a quantidade de Senecio brasiliensis no pasto. Não havia criação de ovinos no local.

O proprietário observou que um dos animais estava separado do lote e apresentava sintomas nervosos (andar a esmo ou em círculo, incoordenação e agressi-vidade), vindo a óbito no dia seguinte. Recomendou-se o abate imediato dos demais animais. Há anos que lotes de 15-20 bois eram mantidos no mesmo local, da desmama até o abate.

\section{Achados de necropsia}

O fígado esteve sempre afetado, de tamanho normal ou ligeiramente aumentado, consistência endurecida, superfície lisa e coloração laranja-avermelhada com manchas escuras. Ao corte, o parênquima revelava áreas avermelhadas intercaladas com áreas amareladas e uma trama irregular de tecido fibroso de aspecto arboriforme. Vesícula biliar distendida com edema de parede e bile espessa (Figura 2).

Edema subcutâneo da mandíbula, pescoço e peito, abomaso, mesentérico, além de hidrotórax e hidroperitônio. Hemorragias subendocárdicas, subpericárdicas e nas serosas das vísceras abdominais. Edema, hiperemia e hemorragia no pulmão. Em um dos animais foram encontrados fragmentos da planta no rúmen.

\section{Histopatologia}

Os fígados de 11 animais apresentaram lesões degenerativas e inflamatórias severas. Nos demais, as lesões variaram de moderada a leve. A fibrose era mais intensa nos espaços-porta e muitas vezes, estendia-se por entre os lóbulos, acompanhada de infiltração histiolinfoplasmocitária e neutrofílica. Hiperplasia de células epiteliais dos ductos biliares e megalocitose constituiram-se em alterações marcantes e constantemente observadas (Figura 3).

Os cortes histológicos revelaram com freqüência hiperemia dos sinusóides, eritrócitos em espaços de Disse, hemossiderina em células de Küpffer, re- tenção biliar, esteatose, vacuolização e necrose de hepatócitos e desarranjo das trabéculas de Remak (Figura 4). Em um fígado evidenciou-se reação inflamatória granulomatosa com calcificação focal e células gigantes multinucleadas tipo corpo estranho.

No sistema nervoso central de três animais foram observados discretos focos de espongiose, leve satelitose e hemorragia focal perivascular. Num dos cortes existiam áreas com edema na meninge.

Cortes histológicos dos rins de dois animais revelaram vacuolização e lise moderada do epitélio tubular com pigmento biliar intracitoplasmático, presença de proteína na luz de túbulos contornados e nos espaços de Bowman e área com infiltração linfoplasmocitária intersticial.

Havia focos de hemorragia no endocárdio e no pericárdio e leve infiltração focal histiolinfoplasmocitária no miocárdio.

Fragmentos de intestino mostraram hiperemia, hiperplasia de células caliciformes e infiltração linfoplasmocitária na mucosa. Em um dos cortes havia acentuado edema.

Outras lesões freqüentes incluíram hiperemia esplênica, edema de linfonodos, hiperemia, edema e hemorragia focal no pulmão.

\section{Exames de raiva}

O exame de imunofluorescência direta e o teste de inoculação em camundongos resultaram negativos.

\section{DISCUSSÃO E CONCLUSÕES}

O diagnóstico de seneciose em bovinos leiteiros e de corte aqui descrito baseou-se nos sinais clínicos, achados de necropsia, exames histopatológicos e na presença de cerca de $3 \%$ dessa planta contaminando os fardos de alfafa que vinham sendo fornecidos à vontade aos animais jovens e adultos de uma propriedade e na outra, pela grande quantidade de Senecio spp. no pasto, com ingestão confirmada pela presença de fragmentos no rúmen do animal necropsiado. Esses dados são conclusivos e corroboram a opinião de autores de vários países sobre tal enfermidade [1,2,5,6,13,14,18-21].

Embora a planta não seja palatável [18] e predomine no meio rural a crença de que bovinos não comem Senecio spp. [2], nos casos ora relatados, os animais confinados consumiram a planta fenada junto 


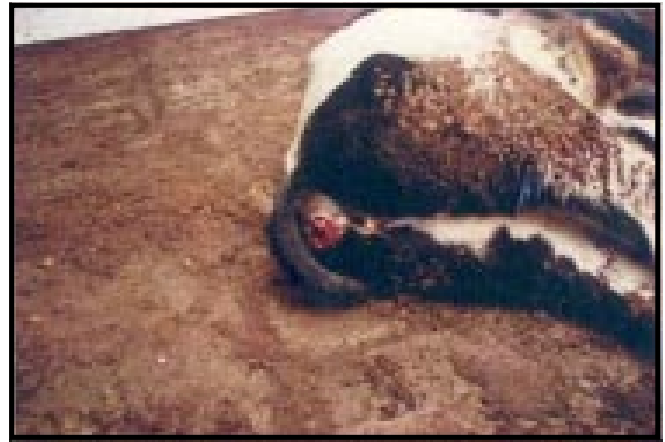

Figura 1. Bovino HPB, fêmea, adulta. Prolapso de reto e paraplegia do trem posterior.

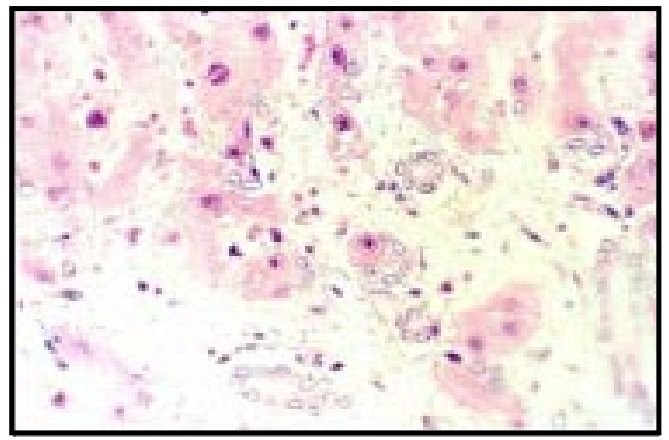

Figura 3. Fígado bov. HPB, fêmea, adulta. Hiperplasia de ductos biliares, megalocitose e fibrose periportal. HE. 400x.

com a alfafa, a qual mantém a sua toxicidade mesmo quando dessecada $[12,13,15,21,22]$. Na propriedade $\mathrm{B}$, os animais estavam sendo criados extensivamente em campo nativo infestado por Senecio spp., repetindo o que vinha sendo feito há anos, sempre com lotes de 15-20 cabeças, sem ocorrência de mortes. Pelas circunstâncias locais admite-se a possibilidade de ter sido um caso isolado de seneciose, pois bovinos adultos podem desenvolver vício após as primeiras ingestões da planta [8].

O efeito tóxico das espécies de Senecio é devido à presença de alcalóides pirrolizidínicos, os quais já foram isolados de outras espécies tóxicas pertencentes às famílias Compositae, Leguminosae e Borraginaceae [3,12]. Na região sul do Brasil e no Uruguai, este tipo de intoxicação em bovinos, após ingestão espontânea ou experimentalmente, já foi constatado em quatro espécies: S. brasiliensis, S. cisplatinus, S. heterotrichius e S. selloi $[1,5,14,15,19,21]$.

Os casos de seneciose são mais freqüentes entre os meses de julho a dezembro [20], possivelmente devido à menor disponibilidade de forragens ou con-

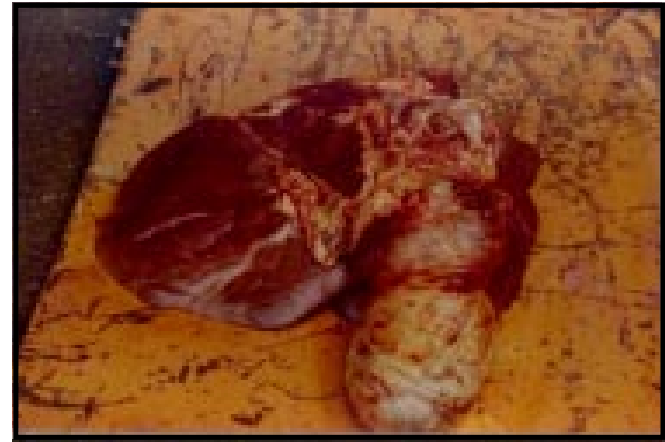

Figura 2. Fígado bov. HPB, fêmea, adulta. Endurecimento (dif. graus) e vesícula distendida com bile.

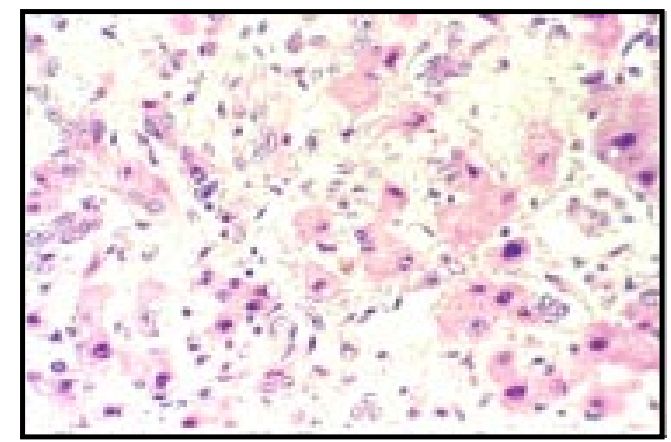

Figura 4. Fígado bov. HPB, fêmea, adulta. Desarranjo das trabéculas de Remak, megalocitose, vacuolização e necrose de hepatócitos. HE. 400x.

dições climáticas adversas [4] nos meses de outono e início de inverno, coincidindo o estágio de brotação da planta em que há maior concentração de alcalóides com a época provável em que ela é consumida [16]. A ingestão repetida de pequenas quantidades da planta em brotação durante tempo prolongado provoca lesão hepática progressiva ao longo de semanas ou meses até que o distúrbio se torne suficientemente grave para que ocorram manifestações clínicas.

Pelo caráter crônico da intoxicação espontânea, casos esporádicos podem ocorrer durante todo o ano $[6,14]$. Corroborando estes autores, a maioria dos nossos casos ocorreu entre julho e novembro e mortes esporádicas foram registradas em outras épocas do ano. Uma medida viável de profilaxia da seneciose em bovinos é o pastoreio junto com ovinos, os quais podem consumir grandes quantidades do vegetal por vários anos sem sinais de intoxicação $[2,4,13]$.

Os sinais clínicos são similares aos previamente observados em casos espontâneos [1,2,5-7,14,19] e experimentais $[10,11,15,21]$, caracterizando-se pela complexidade e falta de uniformidade nas manifesta- 
ções clínicas dos animais afetados, o que pode conduzir a erros no diagnóstico. Isto se explica porque apesar do distanciamento temporal entre causa e efeito dos alcalóides nos casos espontâneos, os animais podem permanecer em bom estado, enquanto pequenas e repetidas doses tóxicas vão pouco a pouco comprometendo o fígado até desencadear o quadro de insuficiência hepática. Mesmo que a sua evolução clínica seja aguda, as lesões histológicas do fígado são sempre crônicas, ou mais raramente, subagudas [1,7,12,14].

Ainda, é interessante ressaltar que a morte do animal pode ocorrer meses ou anos após a última ingestão da planta ou quando a mesma já secou e não é evidente no pasto $[13,22]$. Em outras vezes, o animal que consumiu a planta foi vendido ou transferido para propriedade livre de Senecio spp., vindo a morrer algum tempo depois [5].

O caráter insidioso dos distúrbios neurológicos e digestivos, além de edema de barbela e membros, fotossensibilização e emagrecimento progressivo faz com que os casos de seneciose sejam confundidos com tristeza parasitária, raiva, parasitismo gastrintestinal e outras fitotoxicoses [5,14,20]. Em razão disto é importante fazer a análise conjunta dos dados epidemiológicos, das alterações clínico-patológicas acompanhadas de exames histopatológicos e de exames laboratoriais para o estabelecimento do diagnóstico correto da doença.

As lesões macroscópicas mais importantes consistiram de graus variáveis de fibrose hepática, vesícula biliar distendida, edemas viscerais e cavitários. A fibrose esteve sempre presente em níveis diferentes de distribuição e intensidade, acompanhada ou não de lesões hemorrágico-necróticas. Estes achados necroscópicos estão de acordo com os descritos por outros autores [1,2,5,6,10,11,14,15,17,19-21]. Não encontramos lesões de fotodermatite nos casos estudados [21].

As lesões microscópicas como hepatomegalocitose, fibrose e hiperplasia de células epiteliais dos ductos biliares são características e resultaram da ação dos alcalóides da planta [2,3,14,21]. Em 11 de 16 fígados examinados, as lesões degenerativas e inflamatórias eram severas e nos demais, foram de moderada para leve, que associadas às outras alterações histológicas correspondem, respectivamente, ao quadro crônico e subagudo [21].

Alterações não específicas da seneciose, entre elas, desarranjo das trabéculas de Remak, edema do espaço de Disse, hiperemia, hemossiderina em células de Küpffer, bilestase e hepatócitos degenerados e necróticos também foram observados anteriormente [1,5,11,14].

$\mathrm{Na}$ intoxicação experimental por espécies diferentes de Senecio as lesões renais assemelhamse àquelas já descritas [10,21]. Ainda, a perda de proteínas pelos rins lesados e a hipertensão portal devido à fibrose hepática poderiam explicar a formação de edema, achado marcante na intoxicação por alcalóides pirrolizidínicos. Portanto, o comprometimento grave destes órgãos contribuiria inevitavelmente para o quadro de hipoproteinemia (proteinúria, dificuldade de síntese protéica pelo fígado e aumento da pressão hidrostática portal). A isso se somaria, nos casos crônicos, a redução gradativa ou a falta de ingestão protéica pelo animal $[1,7]$.

Lesões histológicas no sistema nervoso central, caracterizadas por discretos focos de malácia e leve satelitose, hemorragia focal perivascular (3 casos) e edema da meninge (1 caso) estão associados ao quadro clínico de perturbação neurológica freqüentemente descrita na seneciose bovina $[1,5,6,9,11$, $14,18,20,21]$. A lesão nervosa não é provocada pela ação direta do alcalóide, mas, secundariamente, pela incapacidade do fígado lesado em metabolizar a amônia oriunda do intestino em uréia [9]. Em decorrência disto, a hiperamonemia determina as lesões cerebrais e o quadro clínico é denominado encefalopatia hepática ou doença hepatocerebral.

\section{REFERÊNCIAS}

1 Barros C.S.L., Metzdorf L. L. \& Peixoto P.V. 1987. Ocorrência de surtos de intoxicação por Senecio spp. (Compositae) em bovinos no Rio Grande do Sul. Pesquisa Veterinária Brasileira. 7: 101-107.

2 Bull L.B. 1961. Liver diseases in livestock from intake of hepatotoxic substances. Australian Veterinarian Journal. 37: 126-130.

3 Bull L.B., Culvenor C.C.T. \& Dick A.T. 1968. The pyrrolizidine alkaloids. Their chemistry, pathogenicity and other biological properties. Amsterdam: North-Holland Publ., p.293.

4 Dollahite J.W. 1972. The use of sheep and goats to control Senecio poisoning in cattle. Southwest Veterinary. 25: $223-226$.

5 Driemeier D., Barros C.S.L. \& Pilati C. 1991. Seneciose em bovinos. A Hora Veterinária. 10: 23-30. 
6 Fowler M.E. 1968. Pyrrolizidine alkaloid poisoning in calves. Journal of American Veterinary Medical Association. 152: 1131-1137.

7 Gaste L., Marçal W.S., Reichert Neto N.C. R., Reichmann P. \& Carvalho L. 1990. Ascite por cirrose hepática em bovino. Semina. 11:59-61.

8 Harper J.L. \& Wood W.A. 1957. Biological flora of the British Isles (Senecio jacobaea). Journal of Ecology. 45: 617-639.

9 Hooper P.T. 1975. Spongy degeneration in the central nervous system of domestic animals. Part III. Ocurrence and pathogenesis-hepatocerebral disease caused by hyperammonoemia. Acta of Neuropathology. 31: 343-351.

10 Johnson A.E. \& Molyneux R.J. 1984. Toxicity of threadleaf groundsel (Senecio douglasii var. longilobus) to cattle. American Journal of Veterinary Research. 45: 26-31.

11 Johnson A.E., Molyneux R. J. \& Stuart L.D. 1985. Toxicity of Riddell's groundsel (Senecio riddelli) to cattle. American Journal of Veterinary Research. 46: 577-582.

12 Kingsbury J.M. 1964. Poisonous plants of the United States and Canada. New Jersey: Prentice-Hall, 626p.

13 Méndez M.C. 1991. Intoxicação por plantas e micotoxinas hepatotóxicas. Intoxicação por Senecio spp. In: Riet-Correa F., Méndez M.C. \& Schild A.L. (Eds). Intoxicação por plantas e micotoxicoses em animais domésticos. v.1. Montevideo: Hemisferio Sur, pp.43-57.

14 Méndez M.C., Riet-Correa F. \& Schild A.L. 1987. Intoxicação por Senecio spp. (Compositae) em bovinos no Rio Grande do Sul. Pesquisa Veterinária Brasileira. 7: 51-56.

15 Méndez M.C., Riet-Correa F., Schild A.L. \& Martz W. 1990. Intoxicação experimental por cinco espécies de Senecio em bovinos e aves. Pesquisa Veterinária Brasileira. 10: 63-69.

16 Moraes E.C. 1951. Contribuição ao estudo químico-toxicológico do Senecio brasiliensis Less. 79f. São Paulo, SP. Tese (Livre docência). Faculdade de Farmácia e Odontologia, USP.

17 Motidome M. \& Ferreira P.C. 1966. Alcalóides do Senecio brasiliensis Less. Revista da Faculdade de Farmácia e Bioquímica da USP. 4: 38-44.

18 Muth O.H. 1968. Tansy ragwort (Senecio jacobaea), a potential menace to livestock. Journal of American Veterinary Medical Association. 153: 310-312.

19 Podestá M., Tórtora J.L., Moyna P., Izaguirre P.R., Arrillaga B. \& Altamirano J. 1968. Seneciosis in bovinos, su comprobación en el Uruguay. Veterinária. 12: 97-112.

20 Riet-Correa F., Schild A.L., Méndez M.C., Oliveira J.A., Gilturnes C. \& Gonçalves A. 1983. Relatório de atividades e doenças da área de influência no período 1978/1982. Pelotas: Laboratório Regional de Diagnóstico de Pelotas, pp.42-44.

21 Tokarnia C.H. \& Döbereiner J. 1984. Intoxicação experimental por Senecio brasiliensis (Compositae) em bovinos. Pesquisa Veterinária Brasileira. 4: 39-65.

22 Tokarnia C.H., Döbereiner J. \& Peixoto P.V. 2000. Plantas tóxicas do Brasil. Rio de Janeiro: Helianthus, 320p. 